\title{
Ruptured Scar Ectopic Pregnancy: A Near Miss Case
}

\author{
Shraddha A Mevada ${ }^{1}$, Madhuri A Mehendale ${ }^{2}$
}

\begin{abstract}
Aim: Successful management of near miss case of ruptured scar ectopic pregnancy.

Background: Cesarean scar pregnancy (CSP) is an uncommon and potentially life-threatening form of ectopic pregnancy. The incidence of CSP is estimated at between 0.05 and $0.4 \%$ of all pregnancies and is expected to increase in prevalence in parallel with rising cesarean section rates. Case description: We present a case report of 30-year-old gravida 2 para 1 live 1 with previous 1 LSCS done 2 years back i/v/o fetal distress with 8.5 weeks. By date, with pain in abdomen since 2 days which aggravated since 6 hours followed by per vaginal spotting since 1 day came in emergency to our hospital. General condition of the patient on arrival was pulse 140 beats per minute, blood pressure $90 / 60 \mathrm{~mm} \mathrm{Hg}$, per abdominal examination was tenderness present in lower abdomen, per vaginal examination revealed uterus bulky, cervical os admits tip of finger, right fornical tenderness present, and bleeding present.

Conclusion: On emergency laparotomy, after opening the abdominal cavity, ruptured scar ectopic pregnancy was noted, with $4 \times 3 \mathrm{~cm}$ in dimension with hemoperitoneum with $300 \mathrm{~mL}$ of blood, and $80 \mathrm{~g}$ of blood clots were evacuated. Excision of scar with adherent ectopic tissue was done followed by resuturing of remnant uterine wall with continuous interlocking manner with polyglactin 910. Patient was transfused blood accordingly, and postoperative period was uneventful.

Clinical significance: Although clinical and ultrasonography findings can mislead us, ruptured scar ectopic pregnancy should always kept in mind with proper counseling and possibility of torrential hemorrhage and hysterectomy along with availability of senior skilled obstetrician around. Keywords: Maternal morbidity, Ruptured ectopic, Scar ectopic, Transvaginal sonography.

Journal of South Asian Federation of Obstetrics and Gynaecology (2020): 10.5005/jp-journals-10006-1766
\end{abstract}

\section{BACKGROUND}

Cesarean scar pregnancy (CSP) is an uncommon and potentially lifethreatening form of ectopic pregnancy. ${ }^{1,2}$ It is estimated to account for $0.15 \%$ of pregnancies after one cesarean and will likely increase in prevalence due to globally rising cesarean section rates. ${ }^{3,4}$ Abnormal implantation of a CSP probably occurs through defects in the uterine tissue caused by the trauma of a previous cesarean section. The pathophysiology of CSP is not fully understood. A possible mechanism is that trauma caused by a cesarean section creates microscopic tracts through which an implanting blastocyst abnormally invades the affected myometrium. ${ }^{5,6}$

\section{Case Description}

A 30-year-old gravida 2 para 1 live 1 with previous 1 LSCS done 2 years back with 8.5 weeks by date with pain in abdomen since 2 days with per vaginal spotting since 1 day came in emergency to our hospital. General condition of the patient on arrival was pulse- 140 beats per minute, blood pressure was $90 / 60 \mathrm{~mm} \mathrm{Hg}$, per abdominal examination was tenderness present in lower abdomen, per vaginal examination revealed uterus bulky, cervical os admits tip of finger, right fornical tenderness present, and bleeding present. Cardiovascular system-S1S2 +, respiratory system, -air entry bilaterally equal, and normal.

She already had ultrasonography report suggestive of bulky uterus with $10 \times 5 \times 3.8 \mathrm{~cm}$ and heterogeneous $4.1 \times 3.6 \mathrm{~cm}$ echogenic area with gestational sac and fetal pole measuring $14 \mathrm{~mm}$ corresponding 7 weeks 5 days not showing cardiac activity noted in right adnexal area, right ovary could not be visualized separately with $\mathrm{f} / \mathrm{s} / \mathrm{o}$ ruptured right adnexal ectopic pregnancy free fluid in POD and e/o large thick complex heterogeneous collection measuring $10 \times 6.6 \times 5.5 \mathrm{~cm}$ with iliac fossa hematoma.
1,2Department of Obstetrics and Gynecology, LokmanyaTilakMunicipal
Medical College and General Hospital, Mumbai, Maharashtra, India
Corresponding Author: Shraddha A Mevada, Department of
Obstetrics and Gynecology, Lokmanya Tilak Municipal Medical College
and General Hospital, Mumbai, Maharashtra, India, Phone: +91
8655209556, e-mail: drmevadashraddha@gmail.com

How to cite this article: Mevada SA, Mehendale MA. Ruptured Scar Ectopic Pregnancy: A Near Miss Case. J South Asian Feder Obst Gynae 2020;12(2):111-112.

Source of support: Nil

Conflict of interest: None

Investigations were as follows:

CBC-Hemoglobin: $6.2 \mathrm{~g} \%$, total leukocyte count: $15,800 / \mathrm{mm}^{3}$, platelet count: $348,000 / \mathrm{mm}^{3}$.

Patient was taken for emergency laparotomy after opening the abdominal cavity. Ruptured scar ectopic pregnancy was noted (Fig. 1), with $5 \times 4 \mathrm{~cm}$ in dimension with hemoperitoneum with $300 \mathrm{~mL}$ of blood and $80 \mathrm{~g}$ of blood clots evacuated.

Excision of scar with adherent ectopic tissue was done followed by resuturing of remnant uterine wall with continuous interlocking manner with polyglactin 910. Abdomen was closed in layers. With appropriate transfusion of blood and blood products, postoperative period was uneventful followed by discharged on day 4 .

\section{Discussion}

Combined TVS and TAS with Doppler is the current diagnostic modality for CSP with a reported sensitivity of $86.4 \% .{ }^{7,8}$ Magnetic resonance imaging can be used as an adjunct imaging modality to aid in decision-making and operative planning through detailed 


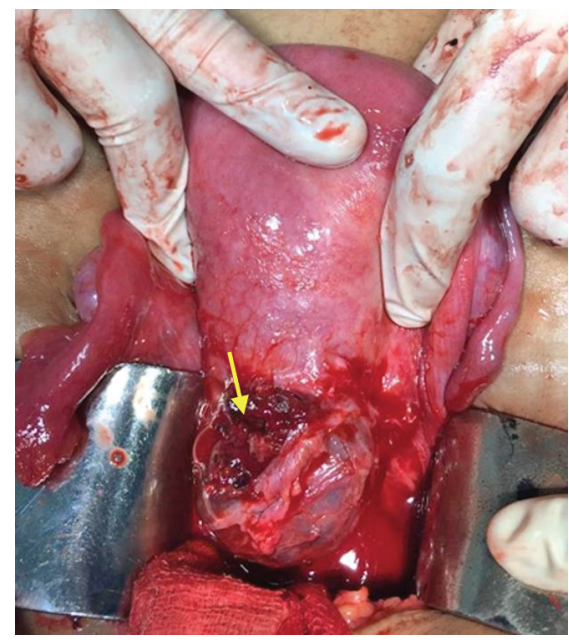

Fig. 1: Intraoperative finding of ruptured scar ectopic pregnancy

characterization of CSP location, depth of myometrial invasion, and presence of bladder involvement. ${ }^{9}$ Subdivision of CSP based on location has been suggested. Type I (endogenic) grows toward the cervicoisthmic space or uterine cavity and may result in a viable pregnancy with high risk of placental site bleeding and morbidly adherent placentae. ${ }^{10}$ Type II (exogenic) invade into the scar defect and progress toward the bladder and abdominal cavity and are associated with uterine rupture. ${ }^{10}$

Medical approaches include administration of intragestational sac methotrexate or long-course systemic methotrexate administration. ${ }^{11}$ Surgical approaches may involve dilation and curettage (D\&C), hysteroscopic resection, surgical excision via open, laparoscopic or transvaginal approaches, or hysterectomy. ${ }^{11}$

\section{LIMITATIONS}

Due to the rarity and heterogeneity of CSP, no guidelines exist on best-practice management. A range of therapies have been described either in isolation or as part of combined management strategies.

\section{Conclusion}

This case highlights the severe risks associated with a CSP and successful management of near miss case of ruptured scar ectopic pregnancy with hemoperitoneum.

\section{Clinical Significance}

Although clinical and ultrasonography findings can mislead us, ruptured scar ectopic pregnancy should always kept in mind with proper counseling and possibility of torrential hemorrhage and hysterectomy along with availability of senior skilled obstetrician around.

\section{Ethical Statement}

Ethical principles were maintained throughout the case and consent of the patient was taken in local language.

\section{References}

1. Jurkovic D, Hillaby K, Woelfer B, et al. First-trimester diagnosis and management of pregnancies implanted into the lower uterine segment cesarean section scar. Ultrasound Obstet Gynecol 2003;21(3):220. DOI: 10.1002/uog.56.

2. Seow KM, Huang LW, Lin YH, et al. Cesarean scar pregnancy: issues in management. Ultrasound Obstet Gynecol 2004;23(3):247-253. DOI: 10.1002/uog.974.

3. Rotas MA, Haberman S, Levgur M. Cesarean scar ectopic pregnancies: etiology, diagnosis, and management. Obstet Gynecol 2006;107(6):1373-1381. DOI: 10.1097/01.AOG.0000218690.24494.ce.

4. Rosen T. Placenta accreta and cesarean scar pregnancy: overlooked costs of the rising cesarean section rate. Clin Perinatol 2008;35(3): 519-529. DOI: 10.1016/j.clp.2008.07.003.

5. Jayaram PM, Okunoye GO, Konje J. Caesarean scar ectopic pregnancy: diagnostic challenges and management options. Obstet Gynaecol 2017;19(1):13-20. DOI: 10.1111/tog.12355.

6. Petersen KB, Hoffmann E, Larsen CR, et al. Cesarean scar pregnancy: a systematic review of treatment studies. Fertil Steril 2016;105(4): 958-967. DOI: 10.1016/j.fertnstert.2015.12.130.

7. Ash A, Smith A, Maxwell D. Caesarean scar pregnancy. BJOG Int J Obstet Gynaecol 2007;114(3):253-263. DOI: 10.1111/j.14710528.2006.01237.x.

8. Osborn DA, Williams TR, Craig BM. Cesarean scar pregnancy: sonographic and magnetic resonance imaging findings, complications, and treatment. J Ultrasound Med 2012;31(9):144. DOI: 10.7863/jum.2012.31.9.1449.

9. Wu R, Klein MA, Mahboob S, et al. Magnetic resonance imaging as an adjunct to ultrasound in evaluating cesarean scar ectopic pregnancy. J Clin Imaging Sci 2013. 3-16. DOI: 10.4103/2156-7514.109758.

10. Gonzalez N, Tulandi T. Cesarean scar pregnancy: a systematic review. J Minim Invasive Gynecol 2017;24(5):731-738. DOI: 10.1016/ j.jmig.2017.02.020.

11. Maheux-Lacroix S, Li F, Bujold E, et al. Cesarean scar pregnancies: a systematic review of treatment options. J Minim Invasive Gynecol 2017;24(6):915-925. DOI: 10.1016/j.jmig.2017.05.019. 